\title{
Safety of Dietary Camelina Oil Supplementation in Healthy, Adult Dogs
}

\author{
Scarlett Burron ${ }^{1}$, Taylor Richards ${ }^{1}$, Keely Patterson ${ }^{1}$, Caitlin Grant ${ }^{2}$, Nadeem Akhtar ${ }^{1}$, Luciano Trevizan ${ }^{3}$, \\ Wendy Pearson ${ }^{1}$ (D) and Anna Kate Shoveller 1,*(D) \\ 1 Department of Animal Biosciences, University of Guelph, Guelph, ON N1G 2W1, Canada; \\ sburron@uoguelph.ca (S.B.); tricha16@uoguelph.ca (T.R.); kpatte10@uoguelph.ca (K.P.); \\ akhtarn@uoguelph.ca (N.A.); wpearson@uoguelph.ca (W.P.) \\ 2 Department of Clinical Studies, University of Guelph, Guelph, ON N1G 2W1, Canada; grantc@uoguelph.ca \\ 3 Departamento de Zootecnia, Universidade Federal do Rio Grande do Sul, \\ Porto Alegre 91540-000, Rio Grande do Sul, Brazil; ltrevizan@ufrgs.br \\ * Correspondence: ashovell@uoguelph.ca
}

check for updates

Citation: Burron, S.; Richards, T.; Patterson, K.; Grant, C.; Akhtar, N.; Trevizan, L.; Pearson, W.; Shoveller, A.K. Safety of Dietary Camelina Oil Supplementation in Healthy, Adult Dogs. Animals 2021, 11, 2603. https://doi.org/10.3390/ani11092603

Academic Editor: Giacomo Biagi

Received: 14 July 2021

Accepted: 31 August 2021

Published: 5 September 2021

Publisher's Note: MDPI stays neutral with regard to jurisdictional claims in published maps and institutional affiliations.

Copyright: (c) 2021 by the authors. Licensee MDPI, Basel, Switzerland. This article is an open access article distributed under the terms and conditions of the Creative Commons Attribution (CC BY) license (https:// creativecommons.org/licenses/by/ $4.0 /)$.
Simple Summary: Dietary sources of omega- 6 and omega- 3 fatty acids are essential in canine diets and provide many health benefits. Camelina (Camelina sativa) is a low-input, high-yield oilseed crop that produces highly unsaturated oil $(\sim 90 \%)$, has a desirable omega- 6 to omega-3 fatty acid ratio, and high concentrations of tocopherols. These attributes make camelina oil a potential alternative to other plant-based oil products for canine nutrition. In the current study, we evaluated the safety of dietary camelina oil supplementation in dogs over a 16-week period in dogs by assessing body weight, body condition score, food intake, and hematology and biochemistry analytes. Differences in the results were minimal compared to dogs fed canola and flaxseed oil, which are regarded as safe for use in canine diets. Therefore, camelina oil can be considered safe for use in the nutrition of adult dogs.

Abstract: This study aimed to determine whether camelina oil is safe for use in canine diets, using canola oil and flax oil as controls, as they are similar and generally regarded as safe (GRAS) for canine diets. A total of thirty privately-owned adult dogs of various breeds (17 females; 13 males), with an average age of $7.2 \pm 3.1$ years (mean $\pm \mathrm{SD}$ ) and a body weight $(\mathrm{BW})$ of $27.4 \pm 14.0 \mathrm{~kg}$ were used. After a 4-week wash-in period using sunflower oil and kibble, the dogs were blocked by breed, age, and size and were randomly allocated to one of three treatment oils (camelina (CAM), flax (FLX), or canola (OLA)) at a level of $8.2 \mathrm{~g}$ oil/100 g total dietary intake. Body condition score (BCS), BW, food intake (FI), and hematological and select biochemical parameters were measured at various timepoints over a 16-week feeding period. All of the data were analyzed with ANOVA using the PROC GLIMMIX of SAS. No biologically significant differences were seen between the treatment groups in terms of BW, BCS, FI, and hematological and biochemical results. Statistically significant differences noted among some serum biochemical results were considered small and were due to normal biological variation. These results support the conclusion that camelina oil is safe for use in canine nutrition.

Keywords: omega-3; omega-6; fatty acids; camelina oil; flaxseed oil; canola oil; canine nutrition

\section{Introduction}

Omega-6 linoleic acid (C18:2n-6; LA) and omega-3 alpha-linolenic (C18:3n-3; ALA) fatty acids are essential in canine diets, as dogs are not able to produce these fatty acids endogenously [1]. Omega-3 (n-3) fatty acids in particular have been shown to have many health-promoting outcomes, including cardioprotective effects [2-4], anti-inflammatory and immune modulating benefits [5-7], and improved skin and coat health properties [8,9]. The ideal n-6:n-3 fatty acid ratio for canine diets is between 5:1 and 10:1, and including $\mathrm{n}-3$ rich ingredients is typically needed to achieve this desired ratio when formulating 
canine diets [7]. Fish oils are a commonly used source of $n-3$ supplementation due to their high levels of eicosapentaenoic acid (EPA) and docosahexaenoic acid (DHA); however, the large-scale use of fish oil in canine diets is not an environmentally sustainable option long-term, leaving a need for plant-based oil alternatives [10-12]. Canola, corn, soybean, and sunflower oil are commonly used plant-based lipid sources in the pet food industry; however, these oils have much higher levels of omega- 6 (n-6) than n-3 fatty acids, with $\mathrm{n}-6: \mathrm{n}-3$ ratios of 1:0.59, 1:0.01, 1:0.12, and 1:0.00, respectively [12,13]. Flax oil does have an $n-6: n-3$ ratio (1:4.19) that is favourable in bringing canine diets to a desirable $n-6: n-3$ ratio, though the continuous cropping of flaxseed oil plants is rare in North America due to their sensitivity to winter climates and diseases or pests $[12,14]$. This leaves room in the market for another plant-based oil that can be easily cultivated and that can provide high n-3 inclusion while still being economically and environmentally sustainable.

Camelina (Camelina sativa), also known as false flax or gold of pleasure, is an oilseed plant of the Brassicaceae (mustard) family that can be grown in a variety of climates, seasons, and soil types due to its short growing season and tolerance to drought and low temperatures [15-18]. Camelina is known to be a low-input, high-yield crop that can perform favourably in poor soils and that is resistant to many pests that affect other oilseed crops $[19,20]$. The camelina oilseed has a high oil yield ( $40 \%$ oil and $\sim 60 \%$ meal), and the resulting oil is highly unsaturated $(\sim 90 \%)$, has a desirable n-6:n-3 ratio (1:1.8), and contains high concentrations of tocopherols [21]. Camelina meal has been approved as safe for use in broiler chickens, cattle fed in confinement for slaughter, and laying hens at an inclusion of up to $10 \%$ of the diet, and the use of camelina oil in fish feed has also been approved [12,22].

The objective of this study was to determine the safety of camelina oil on canine health by comparing it to flaxseed oil (favourably high in n-3 fatty acids) and canola oil (commonly used in pet foods). Since camelina meal has already been approved as safe for use in many livestock species and since flaxseed oil and canola oil are currently used and regarded as safe for use in canine diets, we hypothesized that there would be no negative effects of camelina oil supplementation in adult dogs on food intake (FI), body weight (BW), body condition score (BCS), and hematology and serum biochemistry analytes.

\section{Materials and Methods}

\subsection{Animals, Health Assessment, and Housing}

The present study was approved by the University of Guelph's Animal Care Committee (Animal Use Protocol \#4365) and was in accordance with national and institutional guidelines for the care and use of animals. A total of thirty privately-owned, adult dogs of mixed breeds (17 females: 16 spayed, 1 intact; 13 males: 10 neutered, 3 intact), with an average age of $7.2 \pm 3.1$ years (mean \pm standard deviation, SD) and a BW of $27.4 \pm 14.0$ were recruited to participate in the study. All of the dogs met the following inclusion criteria: clinically healthy on assessment, showing no abnormalities on routine biochemistry and complete blood count (CBC) blood tests, and having no known dietary allergies or skin conditions before being accepted to the study. The dogs were housed at the owner's homes where they followed their usual daily routines.

\subsection{Diets, Study Design, and Food Intake}

All of the dogs were acclimated to a dry extruded commercial kibble (SUMMIT Three Meat Reduced Calorie Recipe, Petcurean, Chilliwack, BC, Canada) (Table 1), sunflower oil (SA Kernel-Trade, Kuiv, Ukraine) (Table 2), and treats (proximate analysis: metabolizable energy $3039 \mathrm{kcal} / \mathrm{kg}$; crude protein minimum $65 \%$; crude fat minimum $5.1 \%$; crude fibre maximum 4.0\%; moisture max 9.56\%) (Beef Tendersticks, The Crump Group, Brampton, ON, Canada) over a 4-week wash-in period. During the wash-in period and throughout the study, the daily portions of food, oil, and treats were pre-weighed by the researchers and were given to owners in two-week intervals to be offered to the dogs daily at a frequency determined by the owners. In order to avoid the occurrence of lipid peroxidation, the oil 
was mixed with the food immediately before feeding. Leftover food was returned to the researchers and was subsequently weighed and recorded to calculate the FI.

Table 1. Diet nutrient content of SUMMIT Three Meat Reduced Calorie Recipe on an as-fed basis and ingredient composition ${ }^{1}$.

\begin{tabular}{cc}
\hline Nutrient Contents & Analyzed Content (As Fed Basis) \\
\hline Moisture (\%) & 8.00 \\
Crude Protein (\%) & 23.0 \\
Nitrogen-Free Extract (\%) & 52.0 \\
Crude Fibre (\%) & 2.80 \\
Crude Fat (\%) & 9.00 \\
Omega 6 (\%) & 2.00 \\
Omega 3 (\%) & 0.83 \\
Linoleic Acid (\%) & 1.90 \\
DHA (\%) & 0.01 \\
Ash (\%) & 7.10 \\
Metabolizable Energy (kcal/kg) & 3613 \\
\hline
\end{tabular}

${ }^{1}$ Chicken meal, whole brown rice, whole white rice, barley, oatmeal, chicken fat (preserved with mixed tocopherols), peas, lamb meal, salmon meal, natural chicken flavour, whole dried egg, sunflower oil, rice bran, flaxseed, dried kelp, dicalcium phosphate, potassium chloride, choline chloride, sodium chloride, calcium carbonate, vitamins (vitamin A supplement, vitamin D3 supplement, vitamin E supplement, niacin, L-ascorbyl-2- polyphosphate (a source of vitamin C), d-calcium pantothenate, thiamine mononitrate, beta-carotene, riboflavin, pyridoxine hydrochloride, folic acid, biotin, vitamin B12 supplement), minerals (zinc proteinate, iron proteinate, copper proteinate, zinc oxide, manganese proteinate, copper sulphate, ferrous sulphate, calcium iodate, manganous oxide, selenium yeast), DL-methionine, glucosamine hydrochloride, chondroitin sulphate, yeast extract, yucca schidigera extract, dried rosemary. ${ }^{2}$ Calculated nitrogen free extract. ${ }^{3}$ Calculated metabolizable energy based on modified Atwater values.

Table 2. Fatty acid profile of camelina oil, canola oil, flax oil, and sunflower oil.

\begin{tabular}{ccccc}
\hline Parameter & Sunflower $^{\mathbf{1}}$ & Canola $^{2}$ & Flax $^{\mathbf{2}}$ & Camelina $^{2}$ \\
\hline $\begin{array}{c}\text { Saturated Fatty } \\
\text { Acids (\%) }\end{array}$ & 9.61 & 6.50 & 8.20 & 9.50 \\
$\begin{array}{c}\text { Monounsaturated } \\
\text { Fatty Acids (\%) }\end{array}$ & 14.1 & 63.8 & 16.6 & 35.2 \\
Polyunsaturated & 76.3 & 29.7 & 75.2 & 55.3 \\
Fatty Acids (\%) & 76.2 & 18.6 & 16.5 & 19.8 \\
Omega 6 (\%) & 0.04 & 11.1 & 58.6 & 35.4 \\
Omega 3 (\%) & N/A ${ }^{2}$ & $<0.1$ & $<0.1$ & $<0.1$ \\
Trans fat (\%) & N/A & & \\
Total Fat (\%) & 99.9 & 100 & 99.9 \\
\hline
\end{tabular}

${ }^{1}$ Numerical values are adapted from Kostik et al. (2013) and only represent generic sunflower oil and not the specific brand used for this study [23]. ${ }^{2}$ Samples run in duplicate by SGS Canada Inc., average values reported. ${ }^{3}$ Abbreviation: N/A, Not Available.

The dogs were initially fed to meet their maintenance energy requirements $(110 \mathrm{kcal}$ $\left.\times \mathrm{BW}(\mathrm{kg})^{0.75}\right)$; then, every two weeks, their BW and BCS were recorded, and the amount of feed was adjusted to maintain BW and BCS throughout the study. Oil was included in the diet at a level of $8.2 \mathrm{~g}$ of oil per $100 \mathrm{~g}$ of total intake, bringing the total dietary lipid content to $20 \%$ inclusion on an as-fed basis. Treats were included in the diet up to $2.5 \mathrm{~g}$ per $100 \mathrm{~g}$ total intake, and the remaining proportion of the diet was provided as kibble.

A randomized complete block design (RCBD) with repeated measures was used for this study. After the wash-in period, the dogs were blocked by breed, age, and size before being randomly allocated to one of three treatment diets: camelina oil (CAM) $(n=10$; 8 females; 2 males), flax oil (FLX) ( $n=10 ; 5$ females; 5 males), or canola oil (OLA) $(n=10$; 4 females; 6 males). Sunflower oil was replaced with either CAM, FLX, or OLA, and feeding continued as described for 16 weeks. 


\subsection{Body Weight and Body Condition Scores}

Body weight was measured every two weeks using a Redmon Precision Digital Pet Scale (Redmon Co., Peru, IN, USA) and BW was then used to calculate dietary food, oil, and treat intake. Body weights on weeks 0, 2, 4, 10, and 16 were measured after an overnight fast and at the same time of day. This allowed the researchers to eliminate variability due to time since last feeding and diurnal effects on BW. For each dog, BCS was assessed on weeks $0,2,4,10$, and 16 using a validated 9-point scale [24].

\subsection{Sample Collection and Analysis}

The dogs were fasted for a minimum of $10 \mathrm{~h}$, and blood samples were collected via cephalic venipuncture using a syringe (Becton, Dickinson and Company, Franklin Lakes, NJ, USA). Of the collected blood, $1 \mathrm{~mL}$ was put into a K2 EDTA $10.8 \mathrm{mg}$ Vacutainer (Becton, Dickinson and Company, Franklin Lakes, NJ, USA) for the hematological indices, and $1 \mathrm{~mL}$ was put into a serum vacutainer (Becton, Dickinson and Company, Franklin Lakes, NJ, USA). Fasted blood samples were collected within the 2 weeks prior (pre-study or baseline) to the start of the wash-in diet with sunflower seed oil supplementation, and on weeks 4 , 10, and 16 after starting the diets supplemented with treatment oils. Collection was taken at these timepoints to allow the researchers the opportunity to assess the effects of both the diet and the treatment oils on standard veterinary diagnostic measures and markers of health and nutritional status using serum and whole blood.

For hematology (complete blood cell count; $C B C$ ), values were determined by the Animal Health Laboratory (AHL) (University of Guelph, Guelph, Canada) using an Advia 2120 hematology analyzer (Siemens Global, Munich, Germany). EDTA samples were stored on ice and were analyzed on the same day, or, in a few cases where the laboratory was closed, blood smears were performed and stored at room temperature, and EDTA samples were refrigerated until analyses were available. Hematological samples were analyzed for blood leukocyte count (WBC), erythrocyte count (RBC), hemoglobin $(\mathrm{Hb})$, hematocrit (Hct) $(\mathrm{RBC} \times \mathrm{MCV})$, mean cell volume $(\mathrm{MCV})$, mean cell hemoglobin $(\mathrm{MCH})(\mathrm{Hb} / \mathrm{RBC})$, mean corpuscular hemoglobin concentration $(\mathrm{MCHC})(\mathrm{Hb} / \mathrm{Hct})$, red cell distribution width (RDW), platelet count, mean platelet volume (MPV), plateletecrit, and total solid (T.S.) protein as well as segmented neutrophil, lymphocyte, monocyte, and eosinophil counts.

For the biochemical analysis, blood from the serum vacutainer $(1 \mathrm{~mL})$ was allowed to clot and was centrifuged at $7200 \times g$ for 15 min using an accuSpin Micro 17 centrifuge (Thermo Fisher Scientific, Waltham, MA, USA). Then, the serum aliquots were collected and were analyzed on same day or were frozen at $-80^{\circ} \mathrm{C}$ until analysis. Serum samples were analyzed for calcium, phosphorus, magnesium, sodium, potassium, chloride, carbon dioxide, anion gap, sodium:potassium (Na:K) ratio, total protein, albumin, globulin, albumin:globulin (A:G) ratio, urea, creatine, glucose, cholesterol, total bilirubin, conjugated bilirubin, free bilirubin, alkaline phosphatase (ALP), steroid-induced ALP, gammaglutamyl transferase (GGT), alanine aminotransferase (ALT), creatine kinase (CK), amylase, lipase, and calculated osmolarity using a cobas 6000 c501 analyzer (Roche Diagnostics Internation AG, Rotkreuz, Switzerland).

The biomarker reference intervals used by AHL for both hematology and biochemistry have been previously determined and used 86 healthy, fasted adult dogs of various breeds, lifestyles, and life stages.

\subsection{Statistical Analysis}

All of the statistical analyses were performed using the PROC GLIMMIX of SAS Studio $^{\circledR}$ software (v.9.4., SAS Institute Inc., Cary, NC, USA). Dog was the experimental unit, and treatment oils and sex were treated as fixed effects. Week was treated as a repeated measure. An analysis of variance (ANOVA) was performed to assess the effects of treatment on BW, BCS, FI, and biochemistry and hematology analytes. Assumptions of residuals for all parameters were assessed using the Shapiro-Wilk to test normality. Residuals were not uniformly distributed for ALP, ALT, CK, and lipase, and as such, data 
were log-transformed prior to analysis. Least-square means were used to assess differences in the means of treatment, week, and treatment by week interactions. When the fixed effects were significant, the means were separated using Tukey-Kramer adjustments. Significance was declared at a $p \leq 0.05$.

\section{Results}

Due to difficulty with blood collection, no hematology or biochemistry samples were obtained from Dog \#21 on week 16. Dog \#14 was put on antibiotics for a urinary tract infection before week 16, and as a result, CBC and biochemistry data were excluded to maintain consistency between all dogs. Dog \#10 dropped out of the study after week 4 for unrelated medical reasons. Further, only partial samples were obtained on five occasions (Dog \#1, week 1; Dog \#9, week 16; Dog \#13, week 4 and week 10; and Dog \#18, week 4), leading to some missing values in the CBC and biochemistry data. All of the aforementioned data were excluded, and statistical analysis was performed using PROC GLIMMIX in order to account for the missing data points and the subsequent unequal number of observations between groups. A total of two additional animals were included in each treatment group to account for possible variation arising from differences in breed, age, and sex of the dogs as well as to account for the possibility of a dog being removed or dropping out of the study or for the possibility of missing data points. Statistically significant differences are outlined below, but the statistical analysis mostly found very small differences between the treatment groups and the values within the given reference ranges and therefore were determined to be biologically insignificant.

\subsection{Body Weight, Body-Condition Score, and Food Intake}

In order to maintain the BW, researchers decreased FI after week 2 (FI = $12.13 \mathrm{~g} / \mathrm{kg} /$ day) and continued to decrease FI until week $16(\mathrm{FI}=10.66 \mathrm{~g} / \mathrm{kg} /$ day) as needed based on the bi-weekly BW measurements of each dog (Table 3). Body weight and BCS were similar among treatments and across weeks $(p>0.05)$. Food intake did not differ among treatment or treatment by week interactions $(p>0.05)$; however, FI did differ across weeks $(p<0.0001)$. Specifically, FI was greater at week 2 than at weeks 10,12, and 14; FI at pre-study and at weeks 4 and 8 was greater than at weeks 6,10,12, and 14, and FI at weeks 6, 10, and 12 was greater at than week $14(p<0.0001$; Table 3$)$.

\subsection{Hematology}

All hematology outcomes are listed in Table 4. No hematological biomarkers differed among the treatment groups $(p>0.05)$; however, pooled data for $\mathrm{MCH}$, total soluble protein, and lymphocyte count differed across weeks $(p<0.05)$. MCH was greater at week 16 than at week 10, but no differences were seen from pre-study or week $4(p=0.0121)$. Total soluble protein was greater at pre-study than at week 4 , but it was not different at weeks 10 and $16(p=0.0002)$, and lymphocyte count was greater at pre-study than at weeks $4,10$, and 16 ( $p=0.0076)$. All mean estimates stayed within the AHL hematology reference range, except for T.S. protein, which had estimates that were $7 \%$ above the reference range.

\subsection{Biochemistry}

All of the biochemistry outcomes are listed in Table 5. The majority of biochemical biomarkers did not differ among treatment groups $(p>0.05)$; however, statistically significant differences among treatments were found for GGT and ALT. GGT was greater in the CAM and FLX treatment groups than in the OLA group $(p=0.0130)$. ALT was greater for the CAM than FLX treatment groups, but neither were different from the OLA group $(p=0.0209)$. 


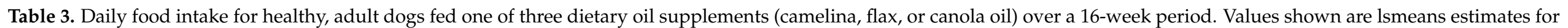
treatment (oil), week, and treatment by week interaction.

\begin{tabular}{|c|c|c|c|c|c|c|c|}
\hline \multicolumn{5}{|c|}{ Food Intake Means Estimate (g/kg/Day) } & \multicolumn{3}{|c|}{$p$-Values } \\
\hline Mean Category & Camelina & Canola & Flax & Mean \pm SEM (Week) & P (Trmt) & P (Week) & P $($ Trmt $\times$ Week $)$ \\
\hline Trmt Mean \pm SEM $^{1}$ & $12.24 \pm 0.697$ & $11.11 \pm 0.697$ & $11.27 \pm 0.698$ & & 0.4733 & $<0.0001$ & 0.8420 \\
\hline Wk 0- Wk 2 & 12.44 & 11.86 & 11.98 & $12.01^{\mathrm{AB}} \pm 0.382$ & & & \\
\hline Wk 2-Wk 4 & 13.00 & 11.58 & 11.82 & $12.13^{\mathrm{A}} \pm 0.403$ & & & \\
\hline Wk $4-$ Wk 6 & 12.98 & 11.46 & 11.66 & $12.04^{\mathrm{AB}} \pm 0.414$ & & & \\
\hline Wk 6- Wk 8 & 11.96 & 11.11 & 11.23 & $11.55^{\mathrm{AB}} \pm 0.420$ & & & \\
\hline Wk 8- Wk 10 & 12.30 & 11.00 & 11.36 & $11.43^{\mathrm{ABC}} \pm 0.467$ & & & \\
\hline Wk $10-$ Wk 12 & 12.27 & 10.77 & 10.99 & $11.34^{\mathrm{BC}} \pm 0.458$ & & & \\
\hline Wk $12-\mathrm{Wk} 14$ & 11.78 & 10.75 & 10.76 & $11.10^{C} \pm 0.438$ & & & \\
\hline Wk $14-$ Wk 16 & 11.23 & 10.37 & 10.38 & $10.66^{\mathrm{D}} \pm 0.396$ & & & \\
\hline
\end{tabular}

${ }^{1}$ Abbreviation: SEM, Standard error of means; Wk, Week. Different superscripts used to reflect differences among weeks $(p<0.05)$. 


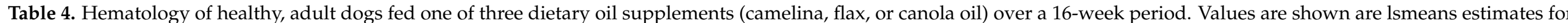
treatment (oil), treatment by week interaction, and week.

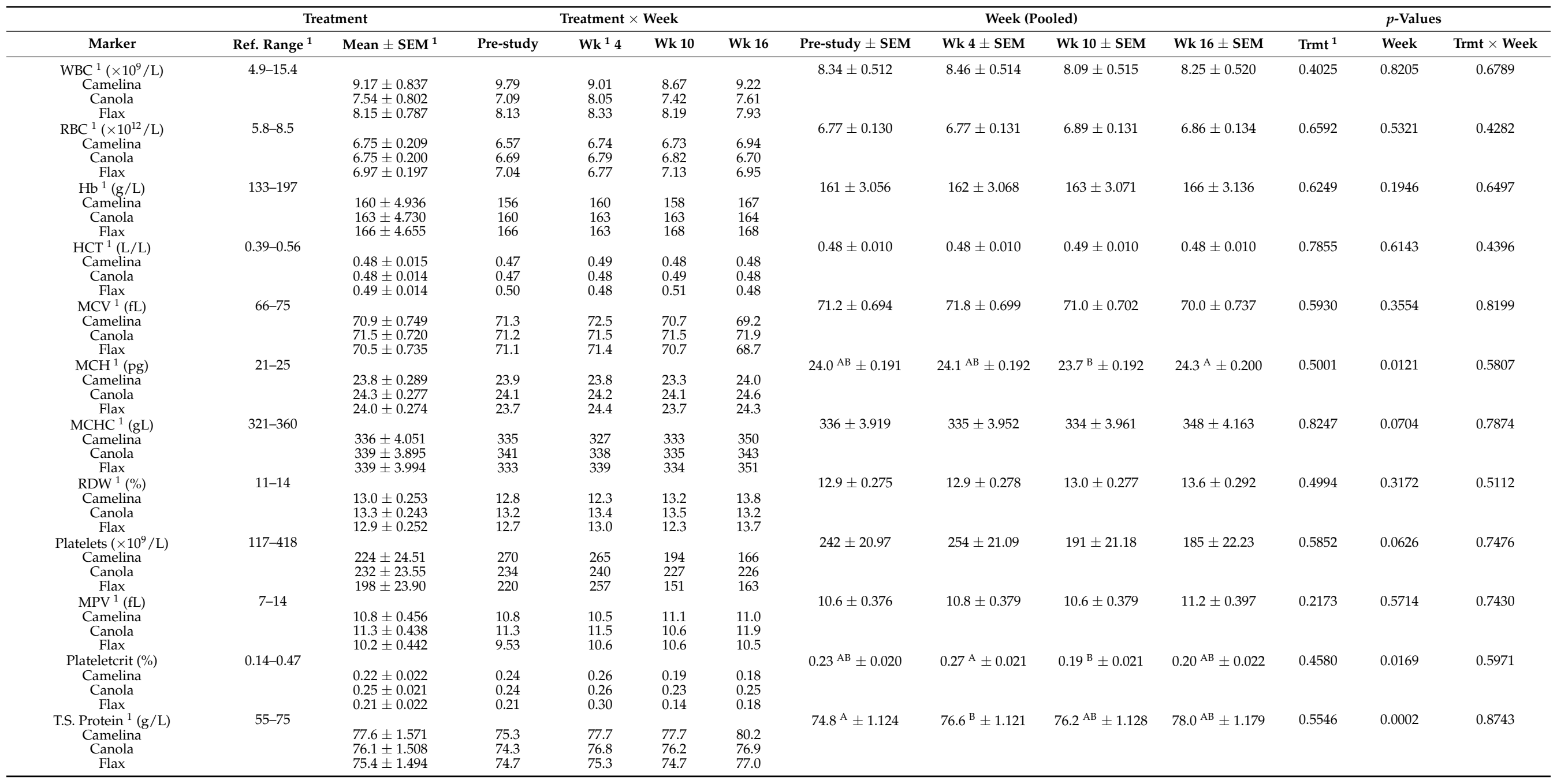


Table 4. Cont.

\begin{tabular}{|c|c|c|c|c|c|c|c|c|c|c|c|c|c|}
\hline \multirow[b]{2}{*}{ Marker } & \multicolumn{2}{|c|}{ Treatment } & \multicolumn{4}{|c|}{ Treatment $\times$ Week } & \multicolumn{4}{|c|}{ Week (Pooled) } & \multicolumn{3}{|c|}{$p$-Values } \\
\hline & Ref. Range $^{1}$ & Mean \pm SEM $^{1}$ & Pre-study & $W^{1} 4$ & Wk 10 & Wk 16 & Pre-study \pm SEM & Wk $4 \pm$ SEM & Wk $10 \pm$ SEM & Wk $16 \pm$ SEM & Trmt $^{1}$ & Week & Trmt $\times$ Week \\
\hline Seg. Neut. Count ${ }^{1}\left(\times 10^{9} / \mathrm{L}\right)$ & $2.9-10.6$ & & & & & & $5.13 \pm 0.339$ & $5.20 \pm 0.340$ & $5.32 \pm 0.340$ & $5.33 \pm 0.344$ & 0.1307 & 0.8461 & 0.8341 \\
\hline Camelina & & $6.02 \pm 0.556$ & 6.08 & 6.02 & 5.82 & 6.17 & & & & & & & \\
\hline Canola & & $4.35 \pm 0.533$ & 3.99 & 4.22 & 4.64 & 4.56 & & & & & & & \\
\hline $\begin{array}{c}\text { Flax } \\
\text { Lymphocyte Count }\left(\times 10^{9} / \mathrm{L}\right)\end{array}$ & $0.8-5.1$ & $5.36 \pm 0.523$ & 5.31 & 5.37 & 5.50 & & $2.13^{\mathrm{A}} \pm 0.131$ & $1.97 \mathrm{AB} \pm 0.132$ & $1.66^{B} \pm 0.132$ & $1.73^{B}+0.135$ & 0.6318 & 0,0076 & 0.3049 \\
\hline Camelina & & $2.01 \pm 0.180$ & 2.34 & 2.03 & 1.66 & 2.01 & & & & & & & \\
\hline Canola & & $1.82 \pm 0.173$ & 2.26 & 1.81 & 1.69 & 1.50 & & & & & & & \\
\hline Flax & & $1.79 \pm 0.171$ & 1.78 & 2.05 & 1.63 & 1.69 & & & & & & & \\
\hline Monocyte Count $\left(\times 10^{9} / \mathrm{L}\right)$ & $0.0-1.1$ & & & & & & $0.42 \pm 0.054$ & $0.35 \pm 0.054$ & $0.40 \pm 0.054$ & $0.41 \pm 0.056$ & 0.6238 & 0.5686 & 0.7791 \\
\hline Camelina & & $0.36 \pm 0.066$ & 0.45 & 0.30 & 0.39 & 0.29 & & & & & & & \\
\hline Canola & & $0.45 \pm 0.063$ & 0.44 & 0.40 & 0.41 & 0.53 & & & & & & & \\
\hline Eosinophil Count $\left(\times 10^{9} / \mathrm{L}\right)$ & $0.08-1.33$ & & & & & & $0.62 \pm 0.115$ & $0.64 \pm 0.114$ & $0.68 \pm 0.114$ & $0.66 \pm 0.117$ & 0.5960 & 0.9441 & 0.7665 \\
\hline Camelina & & $0.79 \pm 0.175$ & 0.82 & 0.83 & 0.75 & 0.79 & & & & & & & \\
\hline $\begin{array}{l}\text { Canola } \\
\text { Flax }\end{array}$ & & $\begin{array}{l}0.57 \pm 0.166 \\
0.58 \pm 0.166\end{array}$ & $\begin{array}{l}0.40 \\
0.63\end{array}$ & $\begin{array}{l}0.55 \\
0.54\end{array}$ & $\begin{array}{l}0.64 \\
0.64\end{array}$ & $\begin{array}{l}0.69 \\
0.52\end{array}$ & & & & & & & \\
\hline
\end{tabular}

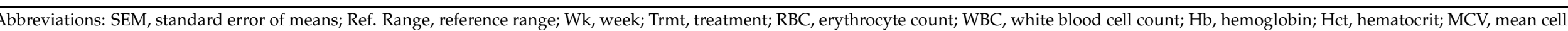

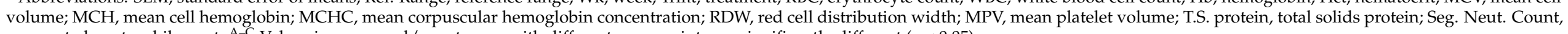
segmented neutrophil count. ${ }^{A-C}$ Values in a row and/or category with different superscripts are significantly different $(p<0.05)$. 


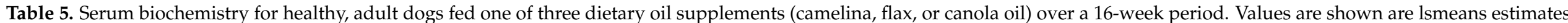
for treatment (oil), treatment by week interaction, and week.

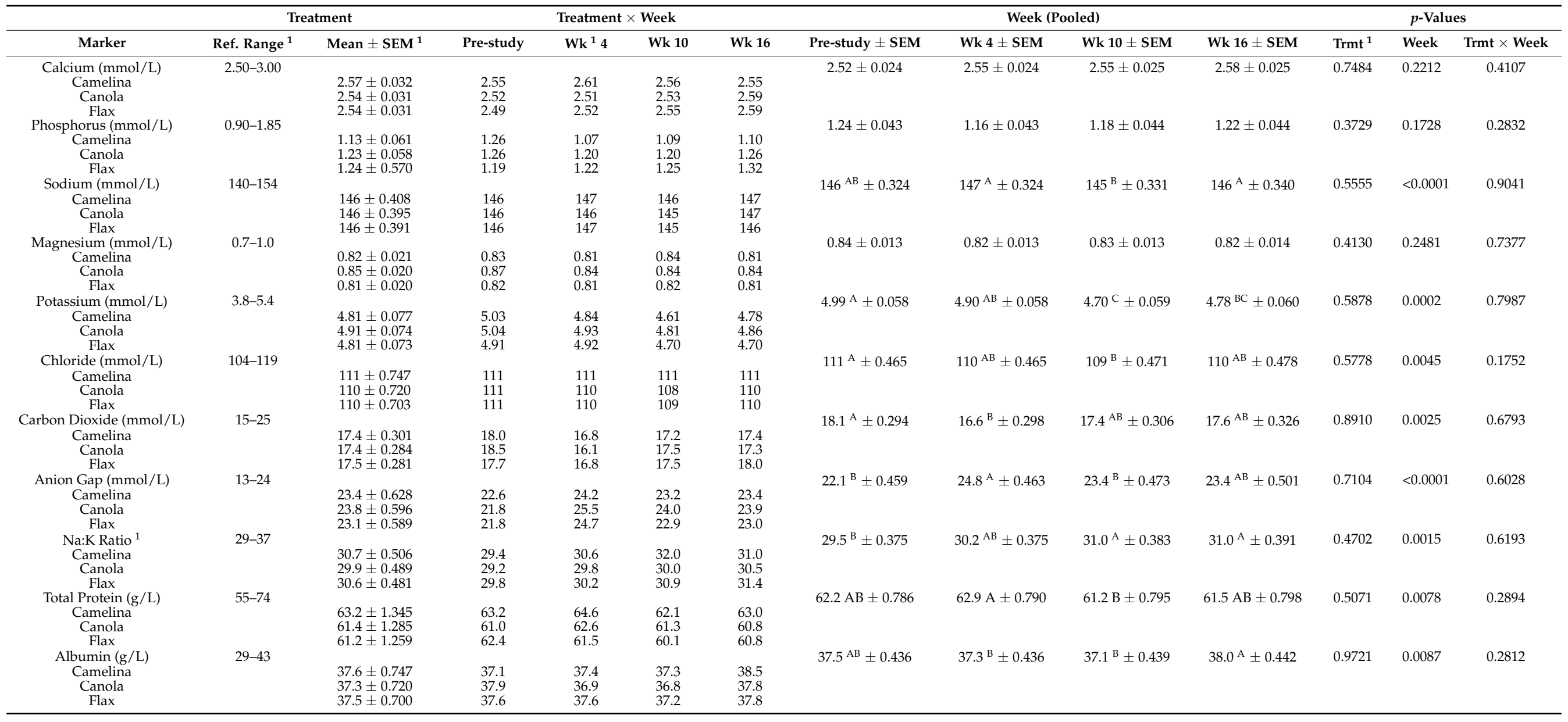


Table 5. Cont.

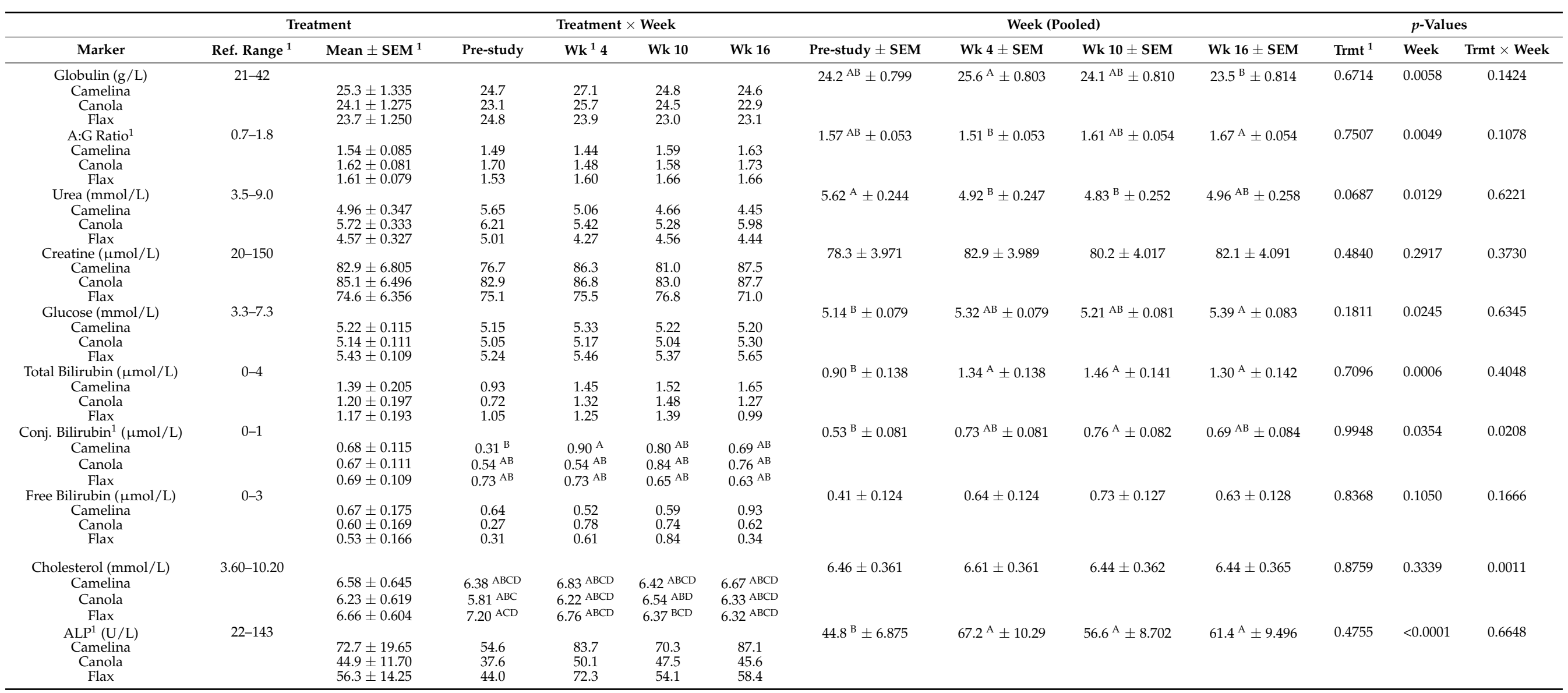


Table 5. Cont.

\begin{tabular}{|c|c|c|c|c|c|c|c|c|c|c|c|c|c|}
\hline \multirow[b]{2}{*}{ Marker } & \multicolumn{2}{|c|}{ Treatment } & \multicolumn{4}{|c|}{ Treatment $\times$ Week } & \multicolumn{4}{|c|}{ Week (Pooled) } & \multicolumn{3}{|c|}{$p$-Values } \\
\hline & Ref. Range $^{1}$ & Mean \pm SEM $^{1}$ & Pre-study & $W^{1} 4$ & Wk 10 & Wk 16 & Pre-study \pm SEM & Wk $4 \pm$ SEM & Wk $10 \pm$ SEM & Wk $16 \pm$ SEM & $\operatorname{Trmt}^{1}$ & Week & Trmt $\times$ Week \\
\hline Steroid-Ind. ALP' ${ }^{1}(\mathrm{U} / \mathrm{L})$ & $0-84$ & & & & & & $11.8^{\mathrm{B}} \pm 3.547$ & $19.2^{\mathrm{A}} \pm 5.919$ & $13.5^{\mathrm{AB}} \pm 4.110$ & $15.2^{\mathrm{AB}} \pm 4.67$ & 0.2262 & 0.0112 & 0.8550 \\
\hline Camelina & & $26.6 \pm 13.52$ & 20.2 & 33.4 & 25.4 & 29.0 & & & & & & & \\
\hline $\begin{array}{l}\text { Canola } \\
\text { Flax }\end{array}$ & & $\begin{array}{l}6.49 \pm 3.796 \\
18.4 \pm 8.687\end{array}$ & $\begin{array}{l}6.21 \\
13.1\end{array}$ & $\begin{array}{l}7.77 \\
27.3\end{array}$ & $\begin{array}{l}5.64 \\
17.1\end{array}$ & $\begin{array}{l}6.51 \\
187\end{array}$ & & & & & & & \\
\hline $\operatorname{GGT}^{1}(\mathrm{U} / \mathrm{L})$ & $0-7$ & & & & & & $1.34 \pm 0.343$ & $1.93 \pm 0.343$ & $1.58 \pm 0.357$ & $0.98 \pm 0.362$ & 0.0130 & 0.2539 & 0.1589 \\
\hline Camelina & & $2.08^{\mathrm{A}} \pm 0.352$ & 0.81 & 2.96 & 2.44 & 2.13 & & & & & & & \\
\hline Canola & & $0.54^{\text {В }} \pm 0.339$ & 1.27 & 0.29 & 0.67 & 0.00 & & & & & & & \\
\hline Flax & & $1.75^{\mathrm{A}} \pm 0.338$ & 1.94 & 2.54 & 1.63 & 0.90 & & & & & & & \\
\hline $\operatorname{ALT}^{1}(\mathrm{U} / \mathrm{L})$ & $19-107$ & & & & & & $40.0^{B} \pm 3.602$ & $49.0^{\mathrm{A}} \pm 4.414$ & $51.4^{\mathrm{A}} \pm 4.700$ & $52.2^{\mathrm{A}} \pm 4.799$ & 0.0209 & 0.0005 & 0.3563 \\
\hline Camelina & & $58.6^{\mathrm{A}} \pm 8.749$ & 43.3 & 58.1 & 70.2 & 66.8 & & & & & & & \\
\hline Flax & & $33.9^{\mathrm{B}} \pm 4.751$ & 30.4 & 36.4 & 33.4 & 35.7 & & & & & & & \\
\hline $\mathrm{CK}^{1}(\mathrm{U} / \mathrm{L})$ & $40-255$ & & & & & & $92.2^{\mathrm{B}} \pm 8.414$ & $108 \mathrm{AB} \pm 9.817$ & $119^{\mathrm{AB}} \pm 11.22$ & $126^{\mathrm{A}} \pm 12.03$ & 0.2677 & 0.0290 & 0.8641 \\
\hline Camelina & & $94.2 \pm 11.22$ & 81.6 & 82.9 & 108 & 108 & & & & & & & \\
\hline Canola & & $123 \pm 14.17$ & 109 & 124 & 120 & 144 & & & & & & & \\
\hline Flax & & $116 \pm 13.09$ & 88.1 & 121 & 129 & 130 & & & & & & & \\
\hline Amylase (U/L) & 299-947 & & & & & & $638^{B} \pm 47.85$ & $688^{\mathrm{A}} \pm 47.85$ & $688^{\mathrm{AB}} \pm 48.14$ & $679 \mathrm{AB} \pm 48.49$ & 0.6248 & 0.0410 & 0.4374 \\
\hline Camelina & & $672 \pm 83.99$ & 643 & 654 & 698 & 693 & & & & & & & \\
\hline Canola & & $730 \pm 80.56$ & 670 & 760 & 739 & 749 & & & & & & & \\
\hline $\begin{array}{c}\text { Flax } \\
\text { Lipase (U/L) }\end{array}$ & & $618 \pm 78.70$ & 601 & 649 & 628 & 594 & & 873 B +8007 & & $898 \mathrm{AB}+8691$ & & & \\
\hline $\begin{array}{l}\text { Lipase }(\mathrm{U} / \mathrm{L}) \\
\text { Camelina }\end{array}$ & $25-353$ & $106 \pm 14.04$ & 113 & 84.1 & 124 & 108 & $107^{A} \pm 9.935$ & $87.3^{\mathrm{B}} \pm 8.097$ & $101^{\mathrm{AB}} \pm 9.589$ & $89.8^{\mathrm{AD}} \pm 8.691$ & 0.0722 & 0.0182 & 0.5192 \\
\hline Canola & & $\begin{array}{l}100 \pm 14.04 \\
75.3 \pm 9.418\end{array}$ & 83.4 & 67.4 & 75.0 & 72.4 & & & & & & & \\
\hline Flax & & $112 \pm 13.97$ & 130 & 117 & 110 & 92.4 & & & & & & & \\
\hline Calc. Osmo. ${ }^{1}(\mathrm{mmol} / \mathrm{L})$ & $\mathrm{N} / \mathrm{A}^{1}$ & & & & & & $292 \mathrm{~A} \pm 0.706$ & $292^{\mathrm{A}} \pm 0.713$ & $289^{B} \pm 0.728$ & $291^{\mathrm{A}} \pm 0.754$ & 0.6718 & $<0.0001$ & 0.8177 \\
\hline $\begin{array}{l}\text { Canola } \\
\text { Flax }\end{array}$ & & $\begin{array}{l}291 \pm 0.895 \\
290 \pm 0.885\end{array}$ & $\begin{array}{l}292 \\
290\end{array}$ & $\begin{array}{l}292 \\
292\end{array}$ & $\begin{array}{l}288 \\
288\end{array}$ & $\begin{array}{l}293 \\
291\end{array}$ & & & & & & & \\
\hline
\end{tabular}

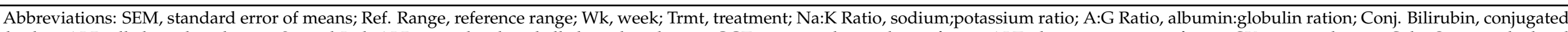

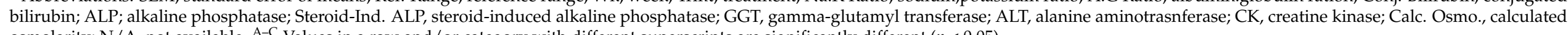
osmolarity; N/A, not available. A-C Values in a row and/or category with different superscripts are significantly different $(p<0.05)$. 
For treatment by week interactions, conjugated bilirubin was greater at week 4 than at pre-study for the CAM treatment group, but no difference was seen with any other treatment by week interactions $(p=0.0208)$. No other differences were seen for treatment by week interactions for the biochemical analytes $(p>0.05)$.

When the treatment groups were pooled, calcium, phosphorus, magnesium, creatine, free bilirubin, and amylase did not differ across weeks $(p>0.05)$; however, all of the other biochemical biomarkers showed differences across weeks $(p<0.05)$. Values were greater at pre-study than at week 4 for $\mathrm{CO}_{2}(p=0.0025)$, urea $(p=0.012)$, and lipase, but these values not different at weeks 10 and $16(p=0.0182)$. Values at weeks 4,10 , and 16 were greater than the pre-study values for total bilirubin $(p=0.0006)$, ALP $(p<0.0001)$, and ALT $(p=0.0005)$. Values at week 16 were greater than the pre-study values for CK $(p=0.0290)$, glucose $(p=0.0245)$, chloride $(p=0.0045)$, and conjugated bilirubin, but these values were not different at weeks 4 or $10(p=0.0354)$. Sodium levels were greater at weeks 4 and 16 than they were at week 10 but were not different from the pre-study values $(p<0.0001)$. Potassium levels were greater at pre-study than they were at weeks 10 and 16, and the values at week 4 and week 16 were greater than the values at week $10(p=0.0002)$. The anion gap values were greater than the pre-study values at weeks 4 and 16, but these values were not different from those at week $10(p<0.0001)$. The Na:K ratio was greater than the pre-study Na:K ratio at weeks 10 and 16, but it was not different from the Na:K ratio at week $4(p=0.0015)$. Total protein was greater at week 10 than it was at week 4 , but it was not different from the pre-study values or the values at week $16(p=0.0086)$. Albumin values were greater at week 16 than they were at weeks 4 and 10, and no difference was seen from the pre-study values $(p=0.0078)$. Globulin values were greater at week 4 than they were at weeks 10 and 16 but were not different than the pre-study values $(p=0.0058)$. The A:G ratio was greater at week 16 than at week 4, but it was not different from the pre-study A:G ratio or the A:G ratio at week $10(p=0.0049)$. Values were greater at week 4 than the pre-study values for steroid-induced ALP $(p=0.0112)$ and amylase $(p=0.0410)$ but were not different from those at weeks 10 or 16 . Calculated osmolarity was greater at week 10 than it was at all other time points $(p<0.0001)$.

All mean estimates for treatment, week, and treatment by week interactions stayed within the AHL reference range for all of the biochemistry biomarkers. It is worth noting, however, that while all means estimates for ALP stayed within the reference range, the raw data showed that four dogs were below the reference range at one or more time points throughout the study, and six dogs exceeded the upper limit of the reference range by at least $25 \%$ at one or more time points throughout the study. A urinalysis was performed for all dogs exceeding the reference range by more than $25 \%$ in order to assess whether there were any abnormalities with the concentrating abilities of their kidneys or any proteinuria that could be indicative of the ALP increase being more than just benign; however, no abnormalities were noted in the urinalysis for any of the dogs.

\section{Discussion}

The purpose of this study was to determine the safety of dietary camelina oil supplementation on canine health by comparing dogs fed camelina oil to dogs fed flaxseed oil or canola oil in order to obtain GRAS certification and an American Feed Control Officials (AAFCO) ingredient definition for camelina oil. Minimal differences were observed in BW, BCS, FI, and hematological and serum biochemical profiles over a 112-day period for dogs fed supplemental camelina oil compared to the control treatment oils, flax and canola.

\subsection{BW, BCS, and Food Intake}

In order to maintain BW and BCS, FI was adjusted throughout the course of the study and was reduced by $11.2 \%$ from baseline (week 0 ) to week 16 . The initial amount of food offered was calculated for all dogs using the same metabolic energy requirement coefficient, regardless of age, sex, or neuter status. Variability based on the aforementioned factors was likely a large contributor to why food intake had to be restricted throughout the course of 
the study, as it has been shown that estimating the maintenance energy requirements of pet dogs based on BW alone is not always as accurate as when husbandry, neuter status, age, sex, and activity levels are factored into the estimation [25]. While this impacted the statistical results for BW, BCS, and FI-and perhaps other variables - the differences between the treatment group results for all of the outcome variables that were measured were small and were determined to be biologically insignificant when compared to normal intervals. Alternatively, if the dogs were allowed to gain or lose weight, then we would have had to account for that as a potential independent variable that could affect all of the parameters that we evaluated.

\subsection{Hematology and Biochemistry}

Current data in dogs are contradictory as to whether high-fat diets are associated with an increase or decrease in serum cholesterol concentrations; however, fat type, rather than total crude fat inclusion, may play a larger role in serum cholesterol concentrations [26-29]. In the present study, there was a significant change in the cholesterol concentrations for the treatment and week interaction, where OLA was significantly higher at week 10 than it was for the pre-study values and where FLX was significantly lower at week 10 than it was for the pre-study values; however, no significance was seen among treatments or weeks, and all of the values remained within the reference range (Animal Health Laboratory, Guelph, ON, Canada). This indicates that neither the high dietary lipid inclusion nor the specific lipid source resulted in a change in the serum cholesterol concentrations of the dogs overall in the present study.

Canine serum ALP activity is a non-specific biomarker for cholestasis and can also be increased in young large breed dogs due to bone growth and increased levels of exogenous or endogenous corticosteroids [30]. The mean serum ALP activity results remained within the reference range for all time points and among all treatment levels; however, a statistically significant increase was seen at weeks 4, 10, and 16 for pooled data compared to pre-study values. These results contradict other studies, where dogs fed high-fat diets showed decreased ALP concentrations over time [26,29]. It remains unclear, however, whether the changes to ALP concentrations observed by Swanson et al. (2004) and Anturaniemi et al. (2020) were related to the dietary lipid content or other factors such as the inclusion levels of proteins, carbohydrates, or other nutrients as well as differences in analytical methods. While we did see an increase in the ALP of $25 \%$ above the reference range for six dogs and even though four dogs were below the reference range at one or more time point, these observations were independent of treatment oil, and all of the dogs remained clinically healthy with no other abnormalities reported by the owners. Increases in ALP are non-specific, and ALP concentrations may be influenced by a variety of factors, including sex, age, and breed [29,31-34]; as such, the large variability in both the current data as well as in the literature suggests that the variability in the ALP results are due to normal biological variation or other non-treatment related factors.

While significant differences were seen among treatments for both GGT and ALT, all values remained within reference range (Animal Health Laboratory, Guelph, ON, Canada). To the authors' knowledge there is presently no conclusive evidence to suggest that dietary composition has a significant effect on either of these liver-related biomarkers in dogs. Swanson et al. (2004) found no significant differences in ALT or GGT concentrations in dogs fed an animal-based diet (20\% crude fat) compared to dogs fed a plant-based diet (8\% crude fat) [29]. Ober et al. (2016) found no significant differences in ALT in dogs fed a high-fat performance diet, a maintenance diet, or a maintenance diet with supplementary corn oil [35]. Similarly, Anturaniemi et al. (2020) found no differences in ALT in dogs fed a heat-processed high carbohydrate diet versus dogs fed a non-processed high-fat diet [26]. In training sled dogs fed two different diets with a high fat content (53.7\% for Diet A and $48.5 \%$ for Diet B), an increase in ALT was measured for Diet B at weeks 7 and 20 from week 0 , but ALT concentrations decreased from weeks 20 to 24 [36]. Though an increase was seen at certain timepoints for ALT, such changes could also be attributed to differences 
in the dietary protein content in the diets [36]. For the present study, both the ALT and GGT levels remained at the lower end of the reference range, and no other significant effects among the treatments were seen for other liver related biomarkers, indicating that the dietary supplementation of CAM, when compared to FLX and OLA, had no negative effects on hepatic health over the 16-week period.

Values for the T.S. protein did not differ among treatments; however, all values were above reference range by up to 7\% (Animal Health Laboratory, Guelph, ON, Canada). This is a semi-quantitative measurement of plasma proteins and is much less accurate than the biochemical analysis of serum total protein included in the biochemical panel, which was within normal ranges. Therefore, the minor changes in the T.S. protein above the reference range were considered irrelevant for the safety assessment of CAM.

An increase was seen in total bilirubin by week and conjugated bilirubin for both week and treatment by week interaction; however, all values remained within the reference range, and no differences were observed among treatments. It is difficult to compare bilirubin values of the present study with existing literature in dogs, as reference ranges show variability among different laboratories; therefore, values cannot be accurately compared [26,37].

\subsection{Considerations}

This study used client-owned dogs, which provided researchers an opportunity to study the real-world effects of camelina oil on canine health, as opposed to in a laboratory setting. This more accurately depicts how camelina oil will affect the canine population as a whole, as the study participants represent various breeds, ages, sizes, and activity levels.

The authors also acknowledge possible limitations that could have resulted from working with client-owned dogs that do not live in a controlled environment. Though the owners were asked to report any deviations from the provided study diet, the researchers could not control for any other possible foods that could have been given to the dogs, with or without the owner's knowledge. Unknown deviations from the diet, the failure of the owners to report any veterinary care, medications, or supplements throughout the study, as well as differences in environments and routines between households could have impacted BW, BCS, FI, and hematology and biochemistry analytes. Since the dogs were brought to campus for blood collection, stress may have had an impact on some concentrations of hematology and biochemistry analytes. Furthermore, the recorded FI could have been impacted by the feeding schedules of owners, failure to return leftover food, or multi-dog households where there is a possibility that the provided food was consumed by other dogs. Finally, because the food was mixed with oil before feeding, researchers were unable to determine oil and food intake separately. Though the dogs were blocked for breed, age, and size, sources of variation due to environmental conditions could not be controlled for in the statistical analysis.

\section{Conclusions}

This study presents information about the effects of dietary camelina oil supplementation on body weight, body condition score, food intake, and hematology and biochemistry analytes compared to canola and flaxseed oil in healthy, adult dogs. Canola and flaxseed oil are already considered to be safe for use in canine diets, and differences in the aforementioned parameters were minimal among treatment groups. As such, we suggest that camelina oil should be considered safe for use in canine nutrition.

Author Contributions: Conceptualization, A.K.S. and W.P.; methodology, A.K.S. and W.P.; study conduct, S.B., T.R., K.P. and C.G.; formal analysis, S.B.; writing-original draft preparation, S.B.; writing-reviewing and editing, S.B., T.R., K.P., C.G., N.A., L.T., W.P. and A.K.S.; funding acquisition, A.K.S. and W.P. All authors have read and agreed to the published version of the manuscript. 
Funding: This research is part of the Diverse Field Crops Cluster with funding from the Canadian Agricultural Partnership program and Smart Earth Camelina Corp. Additional funding was provided by the Natural Sciences and Engineering Research Council of Canada Engage Program. The dog food was provided as a kind gift from Petcurean Pet Nutrition, and the treats were a kind gift from The Crump Group.

Institutional Review Board Statement: This study was conducted in accordance with national and institutional guidelines for the care and use of animals and approved by the University of Guelph Animal Care Committee (AUP \#4365).

Informed Consent Statement: Informed consent was obtained from the owners of all dogs involved in the study.

Data Availability Statement: The data presented in this study are available on request from the corresponding author.

Acknowledgments: The authors would like to thank all of the owners for their support and participation throughout this study as well as all the amazing dogs that we had the opportunity to work with.

Conflicts of Interest: A.K.S. was previously employed by P\&G and Mars Pet Care, serves on the Scientific Advisory Board for Trouw Nutrition, and has received honoraria and research funding from various commodity groups, pet food manufacturers, and ingredient suppliers. C.G. holds the Nestle Purina Professorship in Companion Animal Nutrition. S.B., T.R., K.P., N.A., W.P. and L.T. declare no conflicts of interest.

\section{References}

1. National Research Council Fats and Fatty Acids. Nutrient Requirements of Dogs and Cats; The National Academies Press: Washington, DC, USA, 2006; pp. 81-110.

2. Billman, G.E.; Kang, J.X.; Leaf, A. Prevention of ischemia-induced cardiac sudden death by n-3 polyunsaturated fatty acids in dogs. Lipids 1997, 32, 1161-1168. [CrossRef] [PubMed]

3. Hock, C.E.; Beck, L.D.; Bodine, R.C.; Reibel, D.K. Influence of dietary n-3 fatty acids on myocardial ischemia and reperfusion. Am. J. Physiol. Heart Circ. Physiol. 1990, 259, H1518-H1526. [CrossRef]

4. de Lorgeril, M.; Renaud, S.; Salen, P.; Monjaud, I.; Mamelle, N.; Martin, J.L.; Guidollet, J.; Touboul, P.; Delaye, J. Mediterranean alpha-linolenic acid-rich diet in secondary prevention of coronary heart disease. Lancet 1994, 343, 1454-1459. [CrossRef]

5. Wander, R.C.; Hall, J.A.; Gradin, J.L.; Du, S.H.; Jewell, D.E. The ratio of dietary (n-6) to (n-3) fatty acids influences immune system function, eicosanoid metabolism, lipid peroxidation and vitamin E status in aged dogs. J. Nutr. 1997, 127, 1198-1205. [CrossRef] [PubMed]

6. Gutiérrez, S.; Svahn, S.L.; Johansson, M.E. Effects of omega-3 fatty acids on immune cells. Int. J. Mol. Sci. 2019, 20, 5028. [CrossRef] [PubMed]

7. Vaughn, D.M.; Reinhart, G.A.; Swaim, S.F.; Lauten, S.D.; Garner, C.A.; Bourdeaux, M.K.; Spano, J.S.; Hoffman, C.E.; Conner, B. Evaluation of effects of dietary n-6 to n-3 fatty acid ratios on leukotriene B synthesis in dog skin and neutrophils. Vet. Dermatol. 1994, 5, 163-173. [CrossRef]

8. Kirby, N.A.; Hester, S.L.; Rees, C.A.; Kennis, R.A.; Zoran, D.L.; Bauer, J.E. Skin surface lipids and skin and hair coat condition in dogs fed increased total fat diets containing polyunsaturated fatty acids. J. Anim. Physiol. Anim. Nutr. 2009, 93, 505-511. [CrossRef]

9. Logas, D.; Kunkle, G.A. Double-blinded crossover study with marine oil supplementation containing high-dose icosapentaenoic acid for the treatment of canine pruritic skin disease. Vet. Dermatol. 1994, 5, 99-104. [CrossRef]

10. Brunner, E.J.; Jones, P.J.S.; Friel, S.; Bartley, M. Fish, human health and marine ecosystem health: Policies in collision. Int. J. Epidemiol. 2009, 38, 93-100. [CrossRef] [PubMed]

11. Oken, E.; Choi, A.L.; Karagas, M.R.; Mariën, K.; Rheinberger, C.M.; Schoeny, R.; Sunderland, E.; Korrick, S. Which fish should I eat? Perspectives influencing fish consumption choices. Environ. Health Perspect. 2012, 120, 790-798. [CrossRef] [PubMed]

12. Sarker, P.K.; Bureau, D.P.; Hua, K.; Drew, M.D.; Forster, I.; Were, K.; Hicks, B.; Vandenberg, G.W. Sustainability issues related to feeding salmonids: A Canadian perspective. Rev. Aquac. 2013, 5, 199-219. [CrossRef]

13. AAFCO. Official Publication; Association of American Feed Control Officials: Champaign, IL, USA, 2020.

14. Marchenkov, A.; Rozhmina, T.; Uschapovsky, I.; Muir, A.D. Cultivation of flax. In Flax: The Genus Linum; Muir, A.D., Westcott, N.D., Eds.; CRC Press: New York, NY, USA, 2003; pp. 74-91.

15. Moser, B.R. Camelina (Camelina sativa L.) oil as a biofuels feedstock: Golden opportunity or false hope? Lipid Technol. 2010, 22, 270-273. [CrossRef]

16. Berti, M.; Gesch, R.; Eynck, C.; Anderson, J.; Cermak, S. Camelina uses, genetics, genomics, production, and management. Ind. Crop. Prod. 2016, 94, 690-710. [CrossRef] 
17. Putnam, D.H.; Budin, J.T.; Field, L.A.; Breene, W.M. Camelina: A Promising Low-Input Oilseed. In New Crops; Janick, J., Simon, J.E., Eds.; Wiley: New York, NY, USA, 1993; pp. 314-322.

18. Vollmann, J.; Eynck, C. Camelina as a sustainable oilseed crop: Contributions of plant breeding and genetic engineering. Biotechnol. J. 2015, 10, 525-535. [CrossRef]

19. Zubr, J. Oil-seed crop: Camelina sativa. Ind. Crops Prod. 1997, 6, 113-119. [CrossRef]

20. Séguin-Swartz, G.; Eynck, C.; Gugel, R.K.; Strelkov, S.E.; Olivier, C.Y.; Li, J.L.; Klein-Gebbinck, H.; Borhan, H.; Caldwell, C.D.; Falk, K.C. Diseases of Camelina sativa (false flax). Can. J. Plant Pathol. 2009, 31, 375-386. [CrossRef]

21. Zubr, J.; Matthäus, B. Effects of growth conditions on fatty acids and tocopherols in Camelina sativa oil. Ind. Crop. Prod. 2002, 15, 155-162. [CrossRef]

22. Randall, K.M.; Reaney, M.J.T.; Drew, M. Strategies to increase highly unsaturated omega 3 fatty acids in rainbow trout fed canola, flax and camelina oils. In Proceedings of the 14th International Symposium on Fish Nutrition and Feeding, Qingdao, China, 31 May-4 June 2010.

23. Kostik, V.; Memeti, S.; Bauer, B. Fatty acid composition of edible oils and fats. J. Hyg. Eng. Des. 2013, 4, 112-116.

24. Laflamme, D. Development and validation of a body condition score system for dogs. Canine Pract. 1997, $22,10-15$.

25. Bermingham, E.N.; Thomas, D.G.; Cave, N.J.; Morris, P.J.; Butterwick, R.F.; German, A.J. Energy requirements of adult dogs: A meta-analysis. PLoS ONE 2014, 9, e109681. [CrossRef]

26. Anturaniemi, J.; Zaldívar-López, S.; Moore, R.; Kosola, M.; Sankari, S.; Barrouin-Melo, S.M.; Hielm-Björkman, A. The effect of a raw vs dry diet on serum biochemical, hematologic, blood iron, B12, and folate levels in Staffordshire Bull Terriers. Vet. Clin. Pathol. 2020, 49, 258-269. [CrossRef]

27. Giron, M.D.; Mataix, F.J.; Suarez, M.D. Long-term effects of dietary monounsaturated and polyunsaturated fatty acids on plasma lipids in dogs. Arch. Int. Physiol. Biochim. 1992, 100, 321-326. [CrossRef] [PubMed]

28. Boretti, F.S.; Burla, B.; Deuel, J.; Gao, L.; Wenk, M.R.; Liesegang, A.; Sieber-Ruckstuhl, N.S. Serum lipidome analysis of healthy beagle dogs receiving different diets. Metabolomics 2020, 16, 1-12. [CrossRef]

29. Swanson, K.S.; Kuzmuk, K.N.; Schook, L.B.; Fahey Jr, G.C. Diet affects nutrient digestibility, hematology, and serum chemistry of senior and weanling dogs. J. Anim. Sci. 2004, 82, 1713-1724. [CrossRef]

30. Hedhammer, A. Nutrition related orthopaedic diseases. In Manual of Companion Animal Nutrition and Feeding; Kelly, N., Wills, J., Eds.; The Iowa State University Digita: Ames, IA, USA, 1996; pp. 198-206.

31. Diez, M.; Michaux, C.; Jeusette, I.; Baldwin, P.; Istasse, L.; Biourge, V. Evolution of blood parameters during weight loss in experimental obese Beagle dogs. J. Anim. Physiol. Anim. Nutr. 2004, 88, 166-171. [CrossRef] [PubMed]

32. Sharland, D.E. Alkaline phosphatase: The isoenzyme pattern in the elderly and changes in total serum levels with age. Clin. Chim. Acta. 1974, 56, 187-198. [CrossRef]

33. Radakovich, L.B.; Pannone, S.C.; Truelove, M.P.; Oliver, C.S.; Santangelo, K.S. Hematology and biochemistry of aging-Evidence of "anemia of the elderly" in old dogs. Vet. Clin. Pathol. 2017, 46, 34-45. [CrossRef]

34. Nielsen, L.; Kjelgaard-Hansen, M.; Jensen, A.L.; Kristensen, A.T. Breed-specific variation of hematologic and biochemical analytes in healthy adult Bernese Mountain dogs. Vet. Clin. Pathol. 2010, 39, 20-28. [CrossRef]

35. Ober, J.; Gillette, R.L.; Angle, T.C.; Haney, P.; Fletcher, D.J.; Wakshlag, J.J. The effects of varying concentrations of dietary protein and fat on blood gas, hematologic serum chemistry, and body temperature before and after exercise in labrador retrievers. Front. Vet. Sci. 2016, 3. [CrossRef] [PubMed]

36. Querengaesser, A.; Iben, C.; Leibetseder, J. Blood changes during training and racing in sled dogs. J. Nutr. 1994, 124, 2760S-2764S. [CrossRef] [PubMed]

37. Forster, G.M.; Stockman, J.; Noyes, N.; Heuberger, A.L.; Broeckling, C.D.; Bantle, C.M.; Ryan, E.P. A comparative study of serum biochemistry, metabolome and microbiome parameters of clinically healthy, normal weight, overweight, and obese companion dogs. Top. Companion Anim. Med. 2018, 33, 126-135. [CrossRef] [PubMed] 